\title{
Prenatal right ventricular infarction associated with hypoplastic left heart syndrome
}

\author{
Yoshikatsu Saiki, MD, PhD, John D. Dyck, MD, Michael J. Kantoch, MD, Murray A. Robertson, MD, \\ Peter M. Olley, MD, and Ivan M. Rebeyka, MD, Edmonton, Alberta, Canada
}

$\mathrm{P}$ renatal myocardial infarction is rare and usually fatal, especially when involving the right ventricle in hypoplastic left heart syndrome (HLHS). We report a case of HLHS and prenatal right ventricular infarction in which a successful Norwood operation was performed.

\section{Clinical Summary}

A 1-day-old female infant weighing $3860 \mathrm{~g}$ with HLHS was referred for surgical management. She was born to a 26-year-old gravida 2, para 1 woman at 39 weeks' gestation by spontaneous vaginal delivery. HLHS was diagnosed by fetal echocardiography at 37 weeks' gestation. Pregnancy was otherwise uneventful. On admission she received ventilatory assistance and inotropic and prostaglandin infusions. She was tachycardic with a regular rhythm and hypotensive. Transthoracic echocardiography confirmed the prenatal diagnosis of HLHS with mitral and aortic atresia and trivial tricuspid regurgitation. The anteroinferior wall of the right ventricle was thin and akinetic, suggesting transmural infarction (Figure 1). Review of her prenatal echocardiogram revealed a localized akinetic area in the fetal right ventricle, identical to that seen postnatally. We concluded that she had had a prenatal myocar-

\footnotetext{
From the Divisions of Congenital Cardiovascular Surgery and Pediatric Cardiology, University of Alberta, Edmonton, Alberta, Canada.

Received for publication Oct 30, 2000; accepted for publication Nov 9, 2000.

Address for reprints: Ivan M. Rebeyka, MD, 3H2.06 Walter C. Mackenzie Health Sciences Centre, University of Alberta, 8440-112 St, Edmonton, Alberta, Canada T6G 2B7 (E-mail: irebeyka@cha.ab.ca).

J Thorac Cardiovasc Surg 2001;122:180-1

Copyright $\odot 2001$ by The American Association for Thoracic Surgery $0022-5223 / 2001 \$ 35.00+0 \quad \mathbf{1 2 / 5 4 / 1 1 2 9 3 8}$

doi:10.1067/mtc.2001.112938
}

dial infarct. Repeated electrocardiograms showed no abnormalities. Prothrombin time, partial thromboplastin time, and serum antithrombin III and protein C levels were within normal limits.

She was initially in unstable condition with excessive pulmonary blood flow suggested by high systemic oxygen saturations and lactic acidosis. Management included hypoventilation and a high positive end-expiratory pressure to reduce pulmonary blood flow. The systemic perfusion gradually improved and inotropic agents were tapered.

She underwent a Norwood procedure on day 7. Intraoperative findings confirmed HLHS with a 2-mm ascending aorta and 4-mm aortic arch. There was extensive patchy fibrosis of the anterior and inferior wall of the right ventricle. The remaining myocardium contracted relatively well, and the ventricle was not distended. Standard deep hypothermic cardiopulmonary bypass was established and a Norwood repair performed with a pulmonary homograft patch and a $3.5-\mathrm{mm}$ polytetrafluoroethylene vascular graft with 62 minutes of cardiopulmonary bypass, 50 minutes of deep hypothermic arrest, and 49 minutes of aortic crossclamping. The patient was weaned from bypass with inotropic support including dopamine, $5 \mu \mathrm{g} \cdot \mathrm{kg}^{-1} \cdot \mathrm{min}^{-1}$, and epinephrine, $0.2 \mu \mathrm{g} \cdot \mathrm{kg}^{-1}$. $\min ^{-1}$. She had a delayed sternal closure on the seventh day and was extubated on the ninth postoperative day. Her subsequent hospital course was uncomplicated and she was discharged to the referring hospital on the eighteenth postoperative day.

\section{Comment}

Prenatal myocardial infarction is rare and usually lethal and is typically diagnosed at autopsy. Prenatal recognition is uncommon. ${ }^{1}$ Its etiology is usually unknown although several causes have been described. ${ }^{2-5}$ These include coronary artery embolization by placental vascular, or renal vein thrombi via the ductus arteriosus, hereditary coagulation disorders, coronary ostial stenosis, or subintimal fibrous proliferation in the coronary artery wall, mater- 

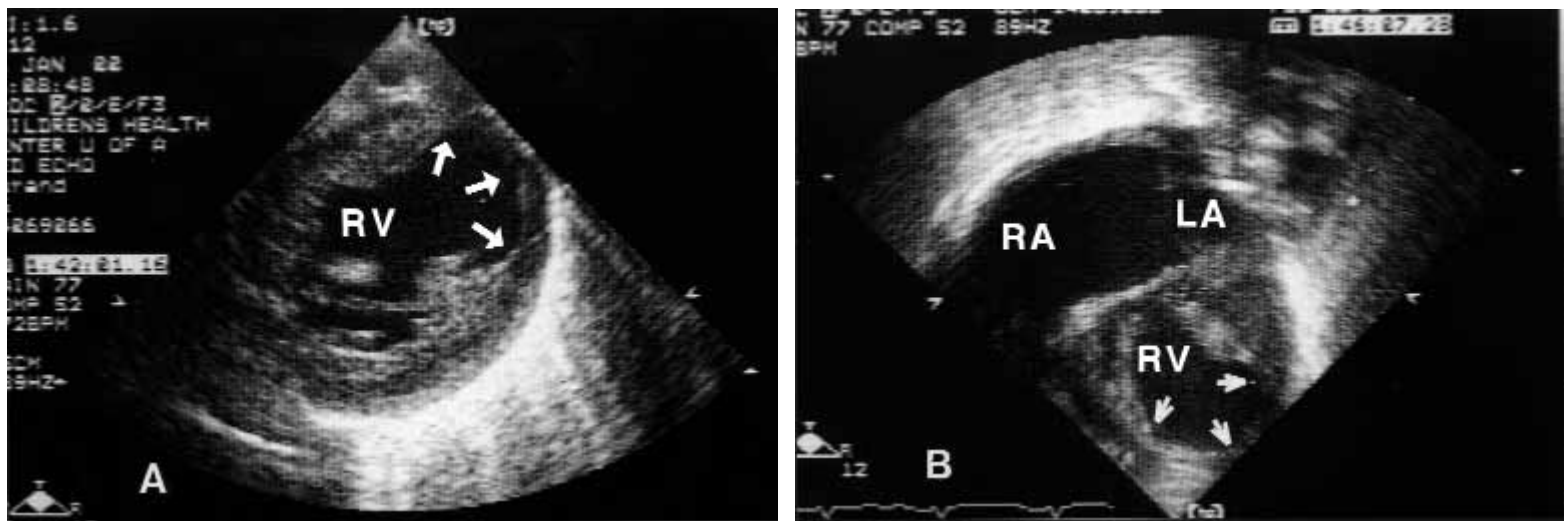

Figure 1. Preoperative echocardiograms. Parasternal short-axis view (A) and apical 4-chamber view (B) show thin-walled akinetic area in the right ventricle (RV) free wall anteriorly and inferiorly. White arrows outline akinetic area. $L A$, Left atrium; $R A$, right atrium.

nal cocaine abuse, sepsis, disseminated intravascular coagulation, and hypoxic fetal distress. The most important risk factor for perinatal myocardial infarction is congenital heart disease, 5,6 especially lesions producing severe myocardial hypertrophy predisposing to subendocardial ischemia. Moodie and associates ${ }^{6}$ reported that 3 of 7 infants who died after the Norwood procedure had infarctions of the right ventricle that antedated surgery by 7 to 10 days as judged by postmortem histopathologic evidence. ${ }^{7}$ Although right ventricular function was normal on preoperative echocardiography, they implicated preoperative infarction as a major cause of mortality. However, whether the infarction occurred before or after birth in their patients is unclear.

We believe this is the first report describing a case of pre-existing transmural right ventricular infarction complicating HLHS, which was successfully managed by the Norwood procedure. In our patient the cause of the infarction remains speculative. There were no documented adverse events during pregnancy, her coagulation system was normal, and there were no coronary artery anomalies. A possible thromboembolism during fetal life cannot be excluded. In patients with the HLHS, coronary perfusion is dependent on retrograde flow via the hypoplastic ascending aorta. When aortic hypoplasia is extreme, transient episodes of fetal distress resulting from asphyxia may be sufficient to cause hypotension leading to coronary hypoperfusion, stasis, and clot formation in the coronary arteries. The relatively high incidence of "subclinical" myocardial infarction observed by Moodie and colleagues ${ }^{6}$ may relate to extreme degrees of ascending aorta hypoplasia. This possibility deserves further study, although Baffa and coworkers ${ }^{7}$ found no difference in right ventricular perfusion in anatomic subgroups of HLHS.
Survival after the Norwood operation depends on adequate right ventricular function, and preservation of its function both before and after surgery is crucial to a successful outcome. Our experience with this patient suggests that a prenatal detection of myocardial infarction should not necessarily preclude a subsequent successful Norwood operation.

\section{References}

1. Patel CR, Judge NE, Muise KL, Levine MM. Prenatal myocardial infarction suspected by fetal echocardiography. $J$ Am Soc Echocardiogr. 1996;9:721-3.

2. Bernstein D, Finkbeiner W, Soifer S, Tutel D. Perinatal myocardial infarction: a case report and review of the literature. Pediatr Cardiol. 1986;6:313-7.

3. Peeters S, Vandenplas Y, Jochmans K, Bougatef A, SeWaele M, DeWolf D. Myocardial infarction in a neonate with hereditary antithrombin III deficiency. Acta Paediatr. 1993;82:610-3.

4. Bulbul ZR, Rosenthal DN, Kleinman CS. Myocardial infarction in the perinatal period secondary to maternal cocaine abuse: a case report and literature review. Arch Pediatr Adolesc Med. 1994;148: 1092-6.

5. Franciosi R, Blanc W. Myocardial infarcts in infants and children. I. A necropsy study in congenital heart disease. J Pediatr. 1968;73:309-19.

6. Moodie DS, Gill CC, Sterba R, Stewart R, Ratliff NB. The hypoplastic left heart syndrome: evidence of preoperative myocardial and hepatic infarction in spite of prostaglandin therapy. Ann Thorac Surg. 1986;42:307-11.

7. Baffa JM, Chen S, Guttenberg ME, Norwood WI, Weinberg PM. Coronary artery abnormalities and right ventricular histology in hypoplastic left heart syndrome. J Am Coll Cardiol. 1992;20:350-8. 